\title{
Quality Management of Regional Economic Competitiveness
}

\author{
V.N. Chaynikov*, V.L. Semenov, A.N. Zakharova, N.V. Voskresenskaya \\ Chuvash state University, Cheboksary, Russia \\ "Corresponding author. Email: chvn66r@mail.ru
}

\begin{abstract}
The regional issue of economic competitiveness development becomes more important for Russia being to a significant extent influenced by economic environment segregation. Thus, a search of optimal approaches to the management of such a complicated object as regional economic competitiveness becomes important. Consequently, this article is focused on development of an integrated system of regional economic competitiveness management allowing to the fullest extent to consider reserves of certain advantages.
\end{abstract}

Keywords: competitiveness, region, management system, conceptual model

\section{INTRODUCTION}

In the environment of competition escalation, increase of competitiveness of the Russian economy is a priority direction of social and economic development of the country. The regional issue of economic competitiveness development becomes more and more important for Russia being to a significant extent influenced by economic environment segregation.

World's economy globalization establishes new competitive conditions of activities of Russian business units effectively influencing all levels and spheres of their interaction with the environment. Thus, a search of optimal approaches to the management of such a complicated object as regional economic competitiveness becomes important.

The most important instrument of the management of regional economic competitiveness is the cluster type of its spatial organization which is, in our opinion, the most efficient one from the point of view of development of investment and innovation activities as well as other areas of activities of business units on the regional territory. Nowadays, among the scientific approaches, the cluster approach to the issue of management of regional economic competitiveness becomes more and more important as the most priority direction having high potential opportunities of development of new competitive advantages of regional economics.

In the well-known works of Russian economic researches, different issues of establishment of mezzolevel object competitiveness management systems have been studied, where an algorithm of development of an efficient object management system was proposed, and a concept of a system of regional competitiveness management was offered based on the following strategic directions of regional competitiveness development: support of efficiency of regional economic management; support of investment and innovation activities; support of competitive environment activities; support human potential development [3, 5, 6-11 , 13-16].

Works by well-known Russian and foreign researches are devoted to the issues of development and operation of systems of object competitiveness management at the micro-level [2, 4, 17, 18, 19, 21, 22, 23].

Thus, in the work [12], an algorithm of development of an efficient object management system was proposed based on the results of an analysis of a wide range of literature sources, contemplating implementation of the following stages of development:

- development and structuring of tasks and objectives of the management system establishment;

- definition of the basic functional management processes;

- determination and application of optional blocks of management tools;

- correction of the objectives and the order of the management system operation.

The achievement of efficient management improvement is always supported by application of advanced ideas, instruments, processes, and organizational forms of management. The main thing in the new management paradigm, as the author of the work [1] mentions, is the new management quality caused by occurrence of new demands to the performance and efficiency of operation of business units of any level accompanied by enlargement of the contents, complexity, and variety of the tasks to solve. The management quality cannot be a result of discreet measures, it is an issue of consistency ensuring competitiveness and efficiency of business unit management. Modelling a trend and environment 
of business unit development, the quality of its management shall be considered as a strategic objective, the achievement of which ensures competitiveness. The management quality, as a result, is represented by a constant ability to generate and implement new competitive advantages of a unit.

To develop a system of regional economic competitiveness management, it is necessary, first of all, to establish the main methodological requirements to its development: first, a system shall be a part of a general social and economic system of a region and considered as its subsystem being an object of analysis and synthesis; second, the system shall be scientifically grounded; third, the system development shall be based on strategic objectives [20].

However, it is worth mentioning that the issues of the development of competitiveness management systems are usually considered in many works at the level of an enterprise and goods and services. A brief analysis of the works in the sphere of the development of object competitiveness management systems shows that, despite of their significant number, this issue remains unsolved at a regional level and requires further elaboration.

\section{METHODS AND MATERIALS}

A concept of management of regional economic competitiveness presupposes a necessity of development of an integrated system that can be represented as a concept model. In modern economic conditions, the development and implementation of the integrated system of regional economic competitiveness management considering predicted long-term and current changes in the external and internal environments is the main task of efficient management at the regional level. In the environment of increasing competition, the issues of development of adaptable systems of regional economic competitiveness management become especially important as the main source of creation of new competitive advantages and strengthening the existing ones and the importance as an object of management.

The development of the concept model of the integrated system of regional economic competitiveness management is a difficult task requiring application of modern research methods to support its development, which is a system of interconnected requirements, approaches, principles, methods, and instruments.

In the process of development of the concept model of the integrated system of regional economic competitiveness management, one of the main requirements is quality of management arrangement achieved through its regulation, where:

-the borders of the system outline are defined, i. e. it is determined, how many and which constitutive subsystems and their elements it includes; -the objectives of the system in general are defined, and the characteristics of its subsystems and their elements are described;

-the ways to achieve the set objectives of both the system in general and each of its subsystems and their elements are planned, and the scheme of their interaction in the process of the system operation is developed.

The management quality as one of the objectives of the development of a system of regional economic competitiveness management is established during objective setting, achieved during the system operation, and assessed during control and correcting in a period of regulation. Besides, the mechanism facilitating the management quality is determined by interconnection of factors of external and internal environments. Quality of the system of regional economic competitiveness management includes management features related to its ability to facilitate efficient results of activity.

The main features of the management quality can be classified with attributes determined by development of corporative culture, a system of decision development and taking, and the efficiency of authority distribution between management bodies.

The developed concept model of the integrated system of regional economic competitiveness management shall, first of all, facilitate quality and efficient taking of strategic managerial decisions focused on increase of economic competitiveness of a region. Consequently, the whole new level of management of regional economic competitiveness can be achieved only through a system of its support based on a cluster approach and reindustrialization.

In the environment of globalization and competition development, competitiveness increases in parallel with the level of competitiveness of not only goods and services but also of business units themselves and their integrations, like financial and industrial groups, holdings, corporations, industrial and regional clusters, and regions in general. Therefore, a task of development of theoretic and methodological aspects of establishment of quality systems of management of the listed units' competitiveness becomes an important strategic issue. This issue is especially important for a regional level and its priority strategic direction - reindustrialization, when a task of development of a new technological industrial base to manufacture high-technological and competitive products has been set.

Thus, the management quality in the modern environment becomes the main requirement to growth of competitiveness of regional economics as one of basic conditions for achievement of a high life level for the population achievable via application of instruments of competitive economics.

The achievement of improvement of the management quality is always facilitated by application of advanced ideas, instruments, processes, and organizational forms of management. The main thing in the new management paradigm is the new management quality caused by the occurrence of new demands to the performance and efficiency of operation of business units of any level 
accompanied by enlargement of the contents, complexity, and variety of the tasks to solve. The management quality cannot be a result of discreet measures, it is an issue of consistency ensuring competitiveness and efficiency of business unit management. Modelling a trend and environment of business unit development, the quality of its management shall be considered as a strategic objective, the achievement of which ensures competitiveness. The management quality, as a result, is represented by a constant ability to generate and implement new competitive advantages of a unit.

Increasing quality of the development of the integrated system of regional economic competitiveness management contemplates:

- clearer task setting for the management system and its subsystems at the respective hierarchy levels making their operation more target-driven;

- consistency of criteria of operation of different level subsystems and increasing efficiency of incentives motivating to consistent actions;

- selection of reasonable structural forms of management arrangement and improvement of management structure at each hierarchy level and of the system in general;

- development and application of efficient up-to-date methods, programs, and algorithms facilitating high quality of managerial task solution;

- implementation of highly efficient operations and processes of data processing based on application of modern computer technologies;

- scientifically grounded improvement of management culture.

Thus, the approach to the development of the concept model of the integrated system of regional economic competitiveness management from the point of view of management quality provides for a higher level of its development.

\section{RESULTS}

In modern conditions of global competition and import substitution, the effectiveness of ISCMRE is largely determined by its ability to create, implement and use a wide range of economic, technological, organizational and managerial innovations in the management of competitiveness of the region's economy. At the same time, the leading role is played

by management innovations, which are directly related to successful innovations in the management subsystems at all its organizational levels: the region, territorial and sectoral clusters and enterprises. System approach to management of innovative activity in ISCMRE involves not only the unity of regulation at all levels of the organization, but a close relationship, consistency of management decisions. Thus, at the enterprise level, innovative management of competitiveness is manifested in the development of intra - enterprise entrepreneurship. Innovations at the enterprise level are an active form of manifestation of NTP, which contributes to the constant updating of the range of products, improving its quality and competitiveness. It better meets the needs of customers of both domestic and foreign markets. At the level of territorial and sectoral clusters, as one of the new organizational forms in ISCMRE, the activation of innovation activities is primarily aimed at improving their competitiveness by creating more effective network structures organized on the principles of competition and cooperation. At the regional level, innovation is the main competitive development of subjects. The activation of an innovative sphere should be carried out in all types of state regulation. There are regulatory, economic, financial state regulations which are based on the forecasts and strategies of innovation policy. Therefore, activation of innovative sphere is one of the important sources of new competitive advantages at all organizational ISCAR levels. At the same time, the methodology for increasing innovative sphere should be based on the use of such modern management technologies as benchmarking, branding, rebranding, coaching, reengineering, outsourcing. At the same time, innovative technologies and management practices recommended for the innovative development of ISCMRE must maintain their focus and essential characteristics of the procedures and algorithms of actions and consider the peculiarities of increasing of economy competitiveness of the particular region.

Self-organization of ISCMRE is the second priority direction of development and it has an ability to restructure outdated organizational structures and methodology for managing the competitiveness of the region's economy to find and use new ways to effectively adapt to changes in the external and internal environment. All these actions allow to achieve its

strategic goals.

Properties for ISCMRE as a self-organizing system are: - openness to external influences, the ability to perceive and recognize external signals, random effects and an adequate responding to them;

- certain freedom for internal changes and internal structural mobility of elements;

- ability to develop horizontal links at all three organized levels.

Innovative development of ISCMRE, its resource potential and other features create the preconditions for the effective improvement of the self-organization of its subsystems and the system as a whole. The main mechanism of selforganization in ISCMRE as a flexible and dynamic system is a nonlinear feedback, which allows it to actively respond to the nature and extent of internal and external changes in an adequate manner.

These reactions are regulated by the control parameter, which is the level of subject competitiveness of the corresponding subsystem. At the same time, the principle of continuous improvement of competitive advantages of ISCMRE subjects is the main force of the search for new ways to manage the mechanism of self-organization. First of all, for further improvement of self-organization mechanisms of ISCMRE is necessary to realize its innovative development. New forms of self-organization 
will appear as a result of joint innovation activities and coordination of goals to improve the competitiveness of all subjects and the region as a whole. The third direction of ISCMRE is the interaction of its subsystems and elements which occur on three levels: regional, cluster, and business entity. Levels of management can be implemented in various forms:

- the cooperation is the interaction between the cluster and the authorities at the regional level; between regional clusters, between enterprises, suppliers of raw materials, materials and components at the cluster level; at the enterprise level it is interaction between its internal divisions which contribute to the achievement of the overall goal of the system; the partnership, it ensures the achievement of synergetic effect as a result of the coordinated activity of all subjects of ISCMRE interaction;

- the communication - consists in the exchange of information obtained with the help of modern communication management tools, in which one ISCMRE subsystem and its elements can affect the

activities of other subsystems and their elements in order to make mutually beneficial decisions for improvement of competitiveness;

- coordination - the regulation of authority, relations within the ISCMRE subsystems and their elements at each hierarchical level and of the system as a whole;
- integration - allows one to interact between enterprises belonging to the cluster and clusters forming the economic complex of the region.

\section{DISCUSSION}

The scientific grounds of the necessity of ISRECM development, the methodical approaches, principles, and requirements to the quality of the development of management systems have been translated into the concept model we have developed (Fig. 1).

The ISRECM concept model represents a closed circuit with the external environment, an "entry", an "exit", and feedback between them. The internal structure of the closed circuit includes three subsystems interconnected by direct and reverse links and located at different levels: a region, a cluster, and a business unit. Each subsystem of a respective level is independent in relation to each below one and includes a controlling subsystem and a controlled one also having direct and reverse links, the environment, the "entry", and the "exit" at their levels.

The contents of the elements of the general management system circuit (Fig. 1), the main of which are the environment, the "entry", and the "exit".

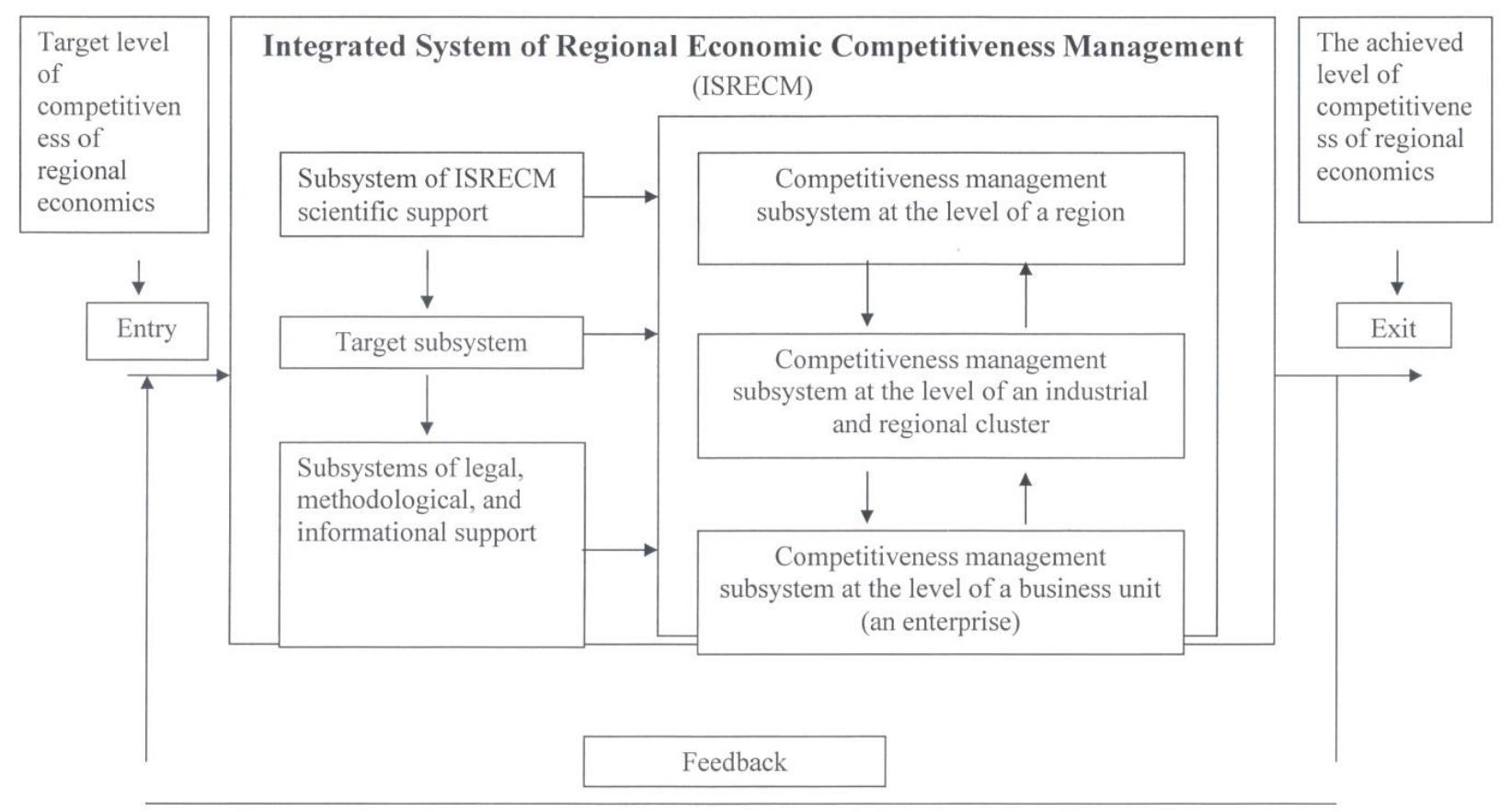

Figure 1 ISRECM Concept Model

The integrated system of regional economic competitiveness management exists in close conjunction with the environment that influences its operation significantly serving as a source of resources to maintain 
its uninterrupted operation. Two main elements of the environment, common for all subsystems and their elements in the ISRECM can be distinguished: macroenvironment and direct environment represented by business environment.

The macro-environment is a part of the environment including economic, political, legal, social, and technological elements. The business environment influences each ISRECM element directly and includes consumers of goods and services, suppliers of stock, materials, and energy, competitors, business partners, infrastructural bodies, state and municipal authorities, and other units.

The direct environment plays an important role in ISRECM operation and interaction of its organizational structures with the environment. Two main issues arise in the interaction of organizational bodies of the business environment at all three levels of management (a region, a cluster, and a business unit): interaction and adaptation; their solution influences significantly the operation of the whole system as an integrated structure.

Development of globalization and information technologies, sophistication and variety of supplied goods and services, their life cycle reduction, occurrence of a large number of competing enterprises, growth of consumers' demands - all these and other changes in the business environment strengthen the influence of the environment on the organizational structures of the ISRECM and their dependence on the environment. The latter force to look for new ways to improve interaction and develop their ability to adapt and react to the dynamics of environment changes flexibly. Such approaches, first of all, include strategic management allowing to forecast any future change of the environment and develop advance measures of an industrial, technological, economic, structural, and behavioral nature for both short- and longterm perspective.

The meaning of the ISRECM "exit" is achievement of the level of regional competitiveness corresponding to a predicted value of the international level and having a long-term potential of economic growth. Then the achieved international level of regional economic competitiveness is an economic basis for improvement of the life level of the region population to international standards.

The target level of the regional economic competitiveness is set quantitatively at the "entry" of the management system (Fig. 1). Such approach facilitates regional leadership.

Similarly, we can develop predicted levels of competitiveness of management entities of the respective subsystems at their "entries" (Fig. 1).

\section{CONCLUSION}

Therefore, the representation of the integrated system of regional economic competitiveness management as a three-level structure (Fig. 1) allows to consider it, on the one hand, at high level within a closed unified circuit, and, on the other hand, in detail at the level of a region, an industrial and regional cluster, and independent business units integrated into it. Such structure of the management system allows to describe the system at its high (regional) level with detailed analysis of primary subsystems at the level of a cluster and an enterprise allowing to the fullest extent to consider competitive advantage reserves at each level. Besides, it allows to represent the task of optimization of regional competitiveness management as a group of numerous specific tasks of each level solved in a certain order. This way, coherent functioning of the system in general is facilitated, where the primary functional units at each hierarchy level are controlled by authorities of the lowest level of management monitored by higher authorities.

Thus, it is needed to conclude that the three-level system of regional economic competitiveness management focused on cluster development with strategic purposes and tasks, well-reasoned actions, and methods of their implementation recorded in it and intended to develop a globally integrated competitive region shall become an efficient instrument for achievement of the main priority of the strategy of social and economic regional development involving achievement of its stable economic growth and international standards of quality of its population's life. In addition, this system allows:

-to perform more efficient competitiveness management at the levels of: a region, a cluster, and business units;

-for cluster enterprises, to be more receptive to innovations;

-to generate impulses to develop competitiveness between cluster enterprises;

-to recognize, apply, and develop new synergetic links between cluster participants.

The main provisions, advice, and conclusions of the article may be used by regional authorities in their activities to increase competitiveness of regional economics, where the most important thing is the developed model of an integrated system of где regional economic competitiveness management as an active instrument to increase the regional economic competitiveness.

\section{REFERENCES}

[1] Yu.Yu. Aleksandrova. Issues of Competitiveness in Modern Economics, Issues of Modern Economics, 1 (21). [Electronic resource]. Link: http://www.meconomy.ru/art.php3? artid=21900

[2] V.A. Vinogradov. Management Quality is the Basis of Modern Management Paradygm, Management in Russia and Abroad, 2006, 6, pp. 9-19.

[3] V.N. Volkova, A.A. Denisov. Basic System Theory and System Analysis: Manual for graduate students, Saint-Petersburg, Publishing House of Saint-Petersburg State Technics University, 1997, pp. 62-64 
Technics Center Federal State Unitary Enterprise, Ed. Magazine Enginery, 2006, p. 372.

Moscow, Eksmo, 2006, p. 464

[5] L. Bertalanffy. General System Theory, Moscow, Progress, 1969.

[6] E.I. Mazilkina, G. A. Panichkina. Competitiveness Management: Manual for graduate students, Moscow, Omega-L, 2007, p. 325.

[7] V.I. Podlesnykh. Theory of Enterprises: Manual for graduate students, Saint-Petersburg, Business Press Publishing House, 2003, p. 336

[8] K.G. Popov, I.N. Sovetov. To the Issue of Application of Natural Management Principles, Management in Russia and Abroad, 2006 6, pp. 3-8.

[9] R. Ackoff, M. Emery. On Purposeful Systems, Moscow, Soviet Radio, 1974.

[10] System Theory and System Analysis in Organizational Management: Manual, edited by V.N. Volkova and A. A. Emelianova, Moscow, Finance and Statistics, 2006.

[11] A.N. Ustinov, V.A. Seleznev. Theory of Enterprise: Manual, Moscow, Moscow State University of Economics, Statistics, and Information Technology, 2005, p. 163

[12] R.A. Fatkhutdinov. Management of Enterprise Competitiveness: Manual, Moscow, Eksmo, 2004, p. 544.

[13] T.G. Philosophova, V.A. Bykov. Competition and Competitiveness: Manual, Moscow, Unity-Dana, 2008, p. 295.

[14] E.V. Freydina. Management System Research: Manual under the general editorship of Yu.V. Gusev, Moscow, Omega-L, 2008, p. 367.

[15] L.N. Chaynikova. Development of Methods of Establishment and Operation of Regional Competitiveness Management System, Abstract of a thesis ... PhD in Economics [Electronic resource]. Link: http://vak.ed.gov.ru/ru/dissertation/ index.php?id54=11846\&from54=6

[16] A.A. Chursin. Management of Enterprise Competitiveness, Moscow, Informatics Research and
[17] T. Andersson, S. Schwaag-Serger, J. Sorvik, E. W. Hansson. The Cluster Policies Whitebook, International Organization for Knowledge Economy and Enterprise Development, Malmo. 2004.

[18] E.M. Bergman, E.J. Feser, Industrial and regional Clusters: Concepts and Comparative Applications / E.M. Bergman, E.J. Feser. Regional Research Institute, WVU. - I999.

[19] C.K. Prahalad, G. Hamel. The Gore Competence of corporation. Harvad Business Reviw, 1990, vol. 68, pp. 79-91.

[20] M. Steiner, C. Hartmann. Looking for the Material and inmaterial Dimensions of Clusters. Paper presented at the Regional Stud es Association Annual Conference on Regionalising the Knowledge Economy. November 21. London 2001.

[21] H. Schmitz. On the Clustering of Small Firms, in: Rasmussen J., Schmitz H., Pieter van Dijk M. (Eds.), Flexible specialization: a new view on small industry, IDS Bulletin (Special Issue), 1992. vol. 23 (3). pp. 64 69.

[22] V.L. Semenov, V.N. Chaynikov, A.N. Zakharova, A.O. Patianova, G.S. Dulina, Elaboration of conceptual framework of providing competitiveness of production with use of forecasting techniques. in: A. Yu. Karpov, N. Martyushev (Eds.), Proceedings of the international conference on trends of technologies and innovations in economic and social studies. Advances in Economics Business and Management Research. 2017. vol. 38, pp. 606-611. DOI https://doi.org/10.2991/ttiess17.2017.99

[23] A.N. Zakharova, V.N. Chaynikov, T.V. Talanova, V.L. Semenov, M.V. Petrova, G.S. Dulina. Economic representations in structure of economic consciousness of student youth in changing world: representations on wealth, poverty, property. in:

L.N. Safiullin, N.K. Gabdrakhmanov

(Eds.), Proceedings of the International Conference Economy in the Modern World (ICEMW 2018).

Advances in Economics, Business and Management Research, vol. 61. 2018. DOI

https://doi.org/10.2991/icemw-18.2018.46 